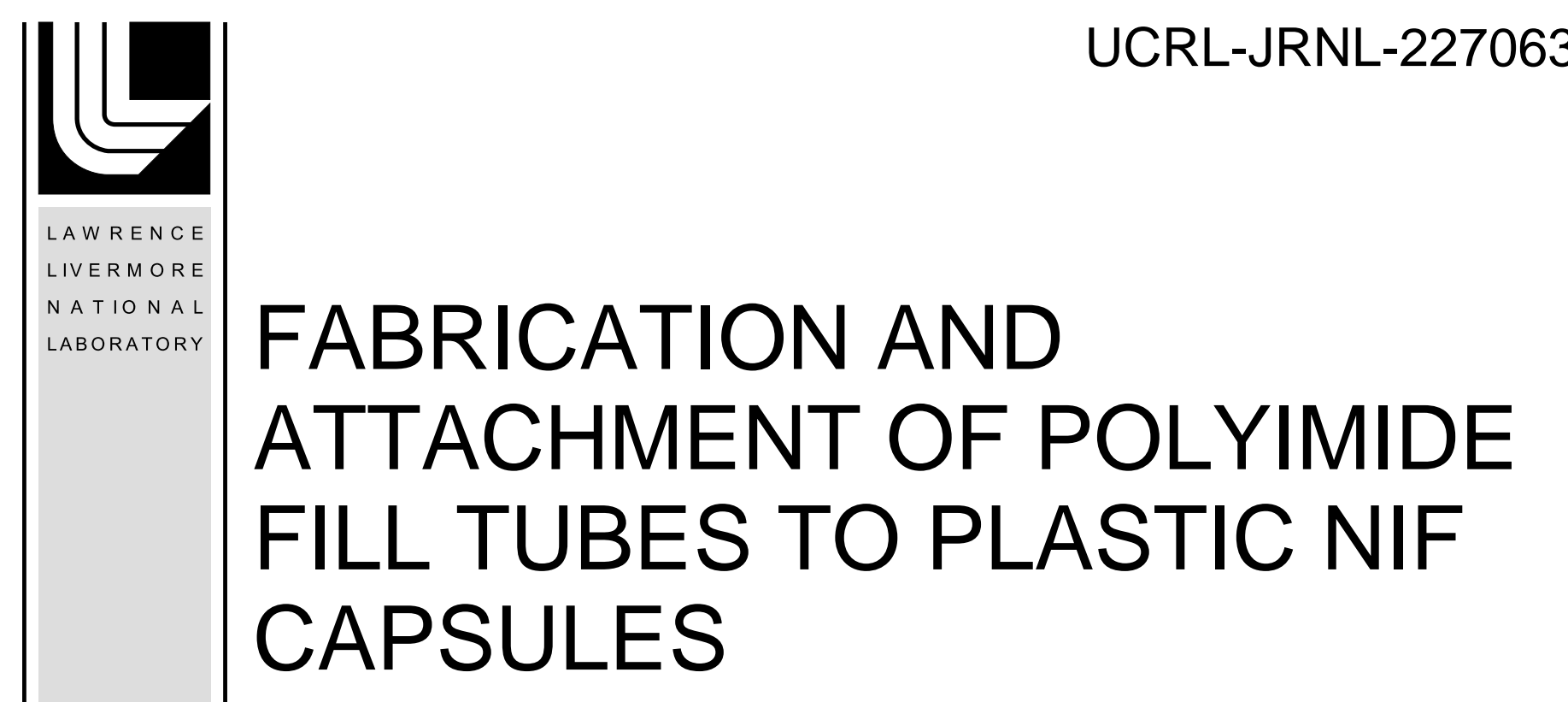

M. Takagi, K. Saito, C. Frederick, A. Nikroo, R. Cook

January 4, 2007

Fusion Science and Technology 
This document was prepared as an account of work sponsored by an agency of the United States Government. Neither the United States Government nor the University of California nor any of their employees, makes any warranty, express or implied, or assumes any legal liability or responsibility for the accuracy, completeness, or usefulness of any information, apparatus, product, or process disclosed, or represents that its use would not infringe privately owned rights. Reference herein to any specific commercial product, process, or service by trade name, trademark, manufacturer, or otherwise, does not necessarily constitute or imply its endorsement, recommendation, or favoring by the United States Government or the University of California. The views and opinions of authors expressed herein do not necessarily state or reflect those of the United States Government or the University of California, and shall not be used for advertising or product endorsement purposes. 


\title{
FABRICATION AND ATTACHMENT OF POLYIMIDE FILL TUBES TO PLASTIC NIF CAPSULES
}

\author{
Masaru Takagi, Kyle Saito, ${ }^{*}$ Christopher Frederick, $\dagger$ Abbas Nikroo, $\dagger$ Robert Cook \\ Lawrence Livermore National Laboratory, Livermore, CA 94550 \\ * General Atomics Internship Student from UC San Diego \\ $\uparrow$ General Atomics, San Diego, CA 92121 \\ takagi@fusion.gat.com
}

We have developed a technique for drawing commercially available polyimide tubing to the required fill tube dimensions. The tubes are then precisely cut with an Excimer laser to produce a clean, flat tip. We have also demonstrated that one can use the Excimer laser to drill less than a $5 \mu \mathrm{m}$ diameter through hole in the $\sim 150$ wall of a NIF dimension GDP shell, and can then create a 10-15 $\mu \mathrm{m}$ diameter, 20-40 $4 \mathrm{~m}$ deep counterbore centered on the through hole with the same laser. Using a home built assembly station the tube is carefully inserted into the counterbore and glued in place with UV-cure epoxy, using a LED UV source to avoid heating the joint. We expect that the same joining technique can be used for Be shells.

\section{INTRODUCTION}

The current plan $^{1}$ for fielding cryogenic capsule targets for the ignition campaign to begin in 2010 at the National Ignition Facility ${ }^{2}$ is to provide the DT fill through a thin fill tube. This fill tube, which can be composed of glass or plastic, will be connected at the capsule wall, which will be laser drilled to create a $5 \mu \mathrm{m}$ or less diameter through hole. The attachment will be facilitated by 20 to $40 \mu \mathrm{m}$ deep counterbore with a diameter not more than $12 \mu \mathrm{m}$, centered on the through hole, which along with appropriate glue will hold the tube. Figure 1 shows the required geometry.

Fill tubes can be made from either glass or plastic. However, low density and low atomic number material is better for an uniform implosion. The effect of the perturbation caused by the fill tube, fill hole, and attachment has been studied by the design group ${ }^{3}$ and has been the subject of an experimental campaign ${ }^{4}$ at the Omega Laser and the University of Rochester. When working with glass fill tubes, we found that the tips are very fragile and tend to break on contact with the surface of the shell, and thus have chosen to explore plastic tubes.

In this paper we report our progress in preparing polyimide fill tubes that meet the required specifications, our laser drilling of glow discharge polymer (GDP) capsules $^{5}$ to create the proper hole geometry, and our initial efforts of attaching these fill tubes to drilled capsules.

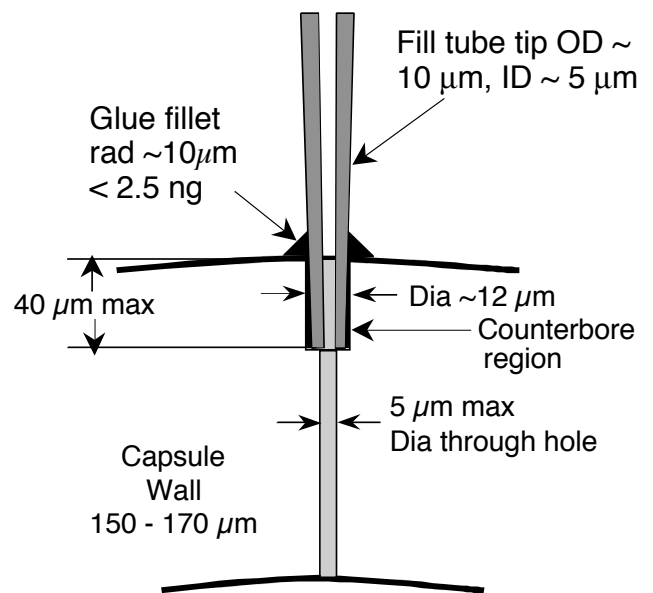

Figure 1. Shown is the structure of the laser drilled hole and counterbore in the shell wall of the capsule.

\section{PREPARATION OF POLYIMIDE FILL TUBES}

We have chosen to work with thermoplastic polyimide tubes, based on their strong resistance to heat, tensile strength and workability. More specifically we have chosen the thermoplastic-polyimide resin "AURUM®," which is produced by Mitsui Chemical in Japan. ${ }^{6}$ We also considered polyetheretherketone (PEEK), a high performance engineered polymer with amazing strength and heat resistant properties, but were unable to control the size due to its very sharp melting point. The AURUM ${ }^{\circledR}$ material has a composition of $\mathrm{C}, \mathrm{H}, \mathrm{N}$, and $\mathrm{O}$ 
only. The specific gravity is 1.33 , the melting point is 388 ${ }^{\circ} \mathrm{C}$, while the $\mathrm{T}_{\mathrm{g}}$ is $250{ }^{\circ} \mathrm{C}$. The tensile strength is $92 \mathrm{MPa}$ at $23{ }^{\circ} \mathrm{C}$ and $189.2 \mathrm{MPa}$ at $-196{ }^{\circ} \mathrm{C}$.

The name of tube prepared from AURUM ${ }^{\circledR}$ is “Thermorex ${ }^{\circledR}$," which is produced by Gunze in Japan. ${ }^{7}$ Thermorex ${ }^{\circledR}$ tubing is used for insulation of electric wires. A number of sizes are currently available as shown in Table I. Clearly these are too large for direct use as a fill tube and must be "pulled" to decrease the outer diameter (OD) of the tubes.

Table I. Size of Thermorex ${ }^{\circledR}$ tubes, measurements in $\mathrm{mm}$.

\begin{tabular}{lccc} 
OD & ID & wall & $\begin{array}{c}\text { aspect } \\
\text { ratio }\end{array}$ \\
0.80 & 0.70 & 0.05 & 14 \\
0.70 & 0.60 & 0.05 & 12 \\
0.48 & 0.40 & 0.04 & 10 \\
0.25 & 0.17 & 0.04 & 4.25 \\
0.23 & 0.15 & 0.04 & 3.75 \\
\hline
\end{tabular}

In order to create tubes with the proper geometry, we constructed a $4 \mathrm{~mm}$ diameter micro-coil puller for heating, along with tube guides above and below the coil as shown in Fig. 2. The tube is suspended in the microcoil heater with a pendant weight and slowly heated to allow the polymer to flow. The tube elongates and thins, then finally breaks to form a thin tip. A magnification of the tube before and during pulling is shown in Fig. 3.

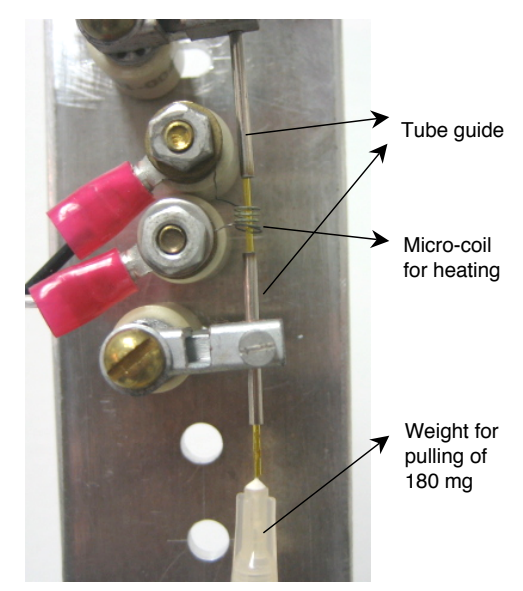

Figure 2. Photo of the tube puller.

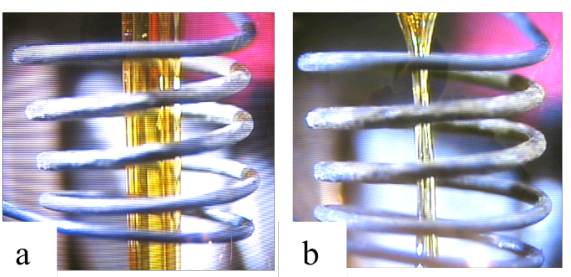

Figure 3. Close-up of the heating coil part of the puller. a: starting, b: pulling.

With the fill tube puller, we are able to consistently produce the same fill tube geometry. We found that the small aspect ratio starting tubes, those with inner diameter (ID) to wall ratios equal to 3.75 and 4.25 , are necessary to make tubes with sufficiently thick walls at the tip. The pulling weight is critical in pulling fill tubes. A pendant weight of 180-200 $\mathrm{mg}$ is correct for NIF dimension tubes. If too light a weight is used, the tube is pulled too thin. If too heavy a weight is used, the tube breaks too soon. Careful control of the heating rate is also critical. Slow heating makes a more uniform-walled tip, thus resulting in fill tubes with thin tips satisfying our required specifications (see Fig. 4).

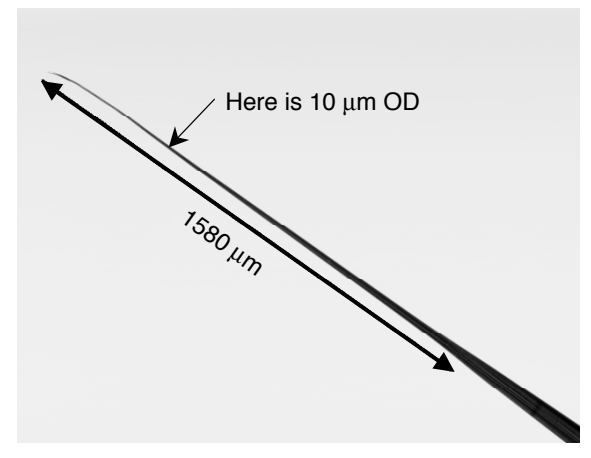

Figure 4. Microscope image of a thin tip fill tube.

Flat tips on the pulled tubes are made by cutting them with an Excimer laser (KRF $248 \mathrm{~nm}, 15 \mathrm{~ns}$ pulses, rep rate $50 \mathrm{~Hz}$ ) using $25-50$ pulses of energy $10-15 \mathrm{~mJ}$. A successful cut is shown in the SEM image at the top of Fig. 5. If the walls are too thin due to starting with too high an aspect ratio tube, we frequently get splitting as shown in the SEM image at the bottom of Fig. 5. 

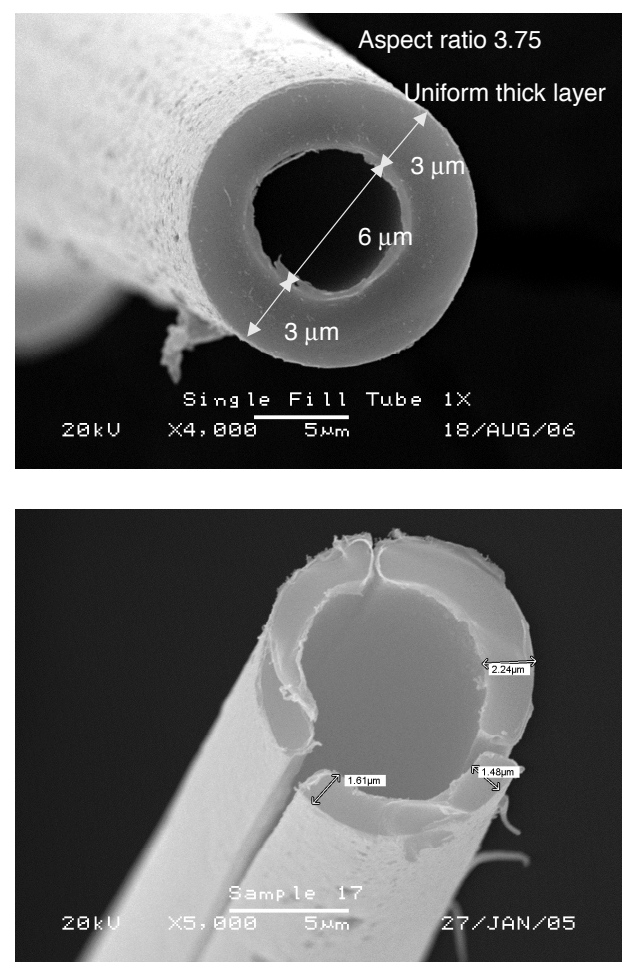

Figure 5. Top: Flat tip with uniform wall after laser etching. Bottom: If wall is too thin splitting can occur.

\section{HOLE DRILLING IN SHELLS}

The drilling of GDP shells is performed using the same Excimer laser. Pulses with energy 12-19 mJ were used, but because of the masking, the energy on target is certainly less. The basic set up is shown in Fig. 6. The diameter of the drilled hole is controlled by the optics and size of mask used. With the $30 \mathrm{X}$ object lens and a $75 \mu \mathrm{m}$ diameter circular hole in the mask, we can drill a $5 \mu \mathrm{m}$ diameter (or less) hole through a $150 \mu \mathrm{m}$ thick GDP shell wall with $500-1000$ pulses. By increasing the mask size to $400 \mu \mathrm{m}$, we can drill a $10-15 \mu \mathrm{m}$ diameter counterbore with $30-70$ pulses. The ranges are partly due to the varying attenuation from the masks. The optimum settings for drilling are still being determined. An example of the combination is shown in Fig. 7 with a through hole and counterbore drilled in a NIF dimension shell. We have found that it is advantageous to drill the small through-hole first, then drill the larger counterbore. In Fig. 7, the hole is through $146 \mu \mathrm{m}$ of GDP ablator (the darker regions are due to Ge-doping) and tapers down from about $4 \mu \mathrm{m}$ to $3 \mu \mathrm{m}$, while the counterbore is about $30 \mu \mathrm{m}$ in depth and tapers from about 15 to $11 \mu \mathrm{m}$. Using current optics, both holes are aligned within $2 \mu \mathrm{m}$.

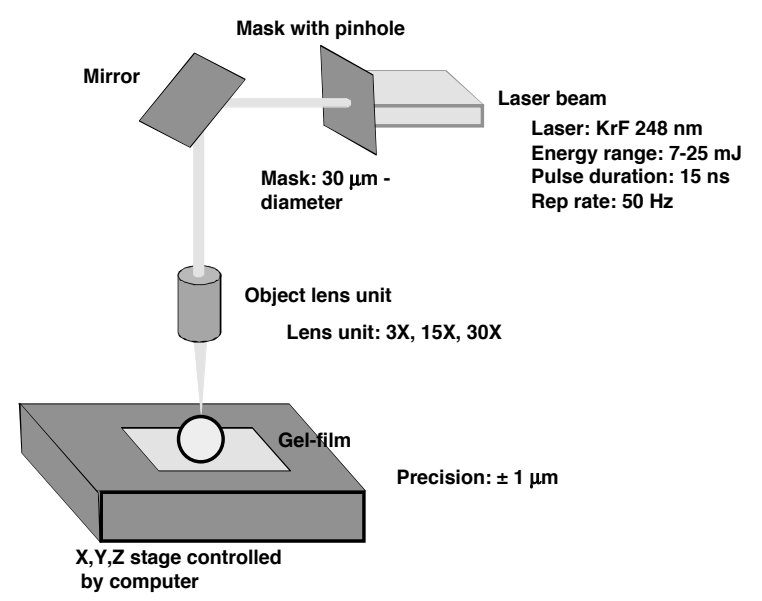

Figure 6. The excimer-laser system for drilling
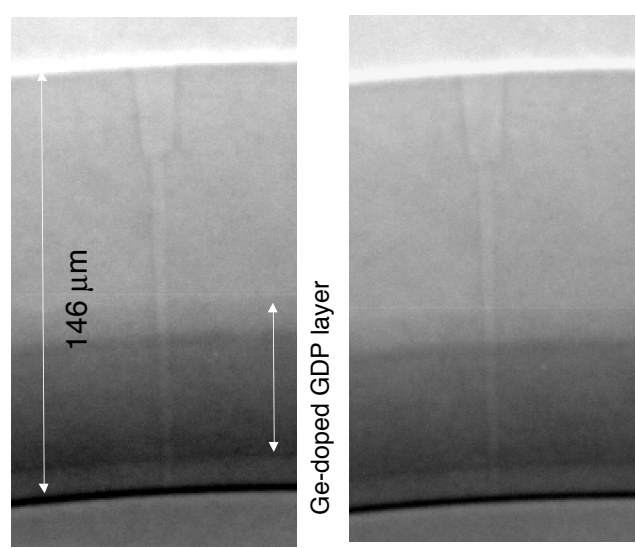

Figure 7. Shown is an X-ray radiograph image of a single through-hole/counterbore. The two images are rotated 90 degrees relative to each other.

\section{FILL TUBE ATTACHMENT}

Our basic approach has been to insert the flat end of the polyimide fill tube into the counterbore, then paint the interface of the tube and counterbore hole with UV curing epoxy glue (Norland 68). We use a micro-injector (Eppendorf, model Femtojet, injection time 0 to100 s, injection pressure 0 to $87 \mathrm{psi}$ ) to control the injection pressure and time for applying the glue. A $10 \mu \mathrm{m}$ or less polyimide tip on the micro-injector allows for precise placement of the glue at the intersection of the fill tube and capsule. The micro-injector also allows us to control the quantity of glue to less than $0.5 \mathrm{ng}$.

The assembly station is shown in Fig. 8. We observe the hole with a 15-30 degree tilted microscope interfaced with a CCD camera. Three XYZ stages are employed. The center $\mathrm{XYZ}$ stage is for shell support, one $\mathrm{XYZ}$ manipulator is for fill tube support, and the glue microinjector is on the other XYZ manipulator. The resolution 
of both the optical system and stages is $\pm 1 \mu \mathrm{m}$. The shell is placed on Gel-Pak Film (Gel-Pak, a division of Delphon Industries, LLC) with the hole on top and centered on the center stage. While watching the hole on the monitors, the fill tube is vertically aligned to the hole and then inserted using the XYZ manipulator. The glue is then applied at the fill tube - counterbore interface. The glue wicks down to fill the counterbore around the fill tube, and then we apply UV to the joint with a low temperature LED source (Panasonic LEDUV system ANUJ5010, maximum power $3200 \mathrm{~mW} / \mathrm{cm}^{2}$ ). Since heating the area of the joint causes distortions, the use of a low temperature source is very important. Building vibration has also been a problem, but we plan to install an anti-vibration table to minimize this problem.

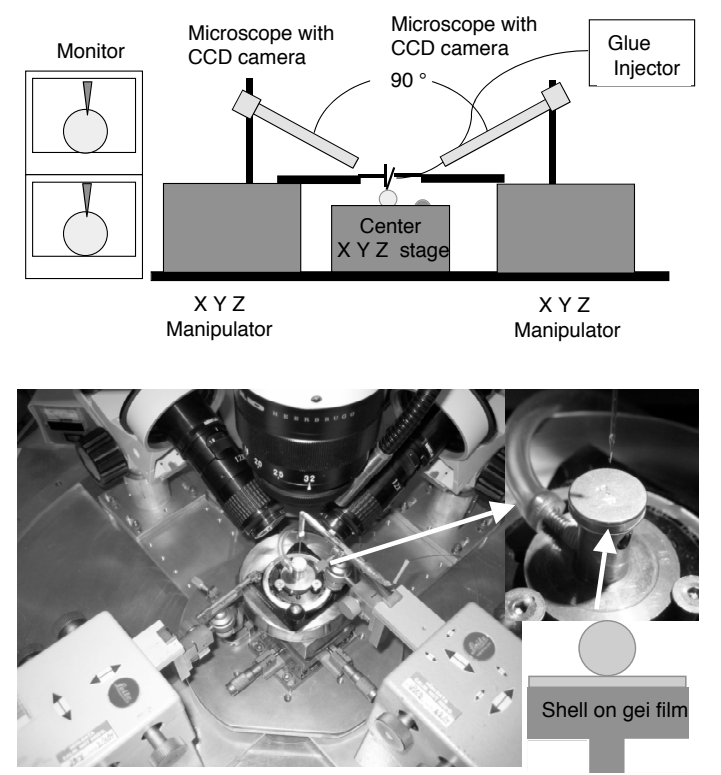

Figure 8. Top: Schematic view of the assembly station, Bottom: Actual view.

An optical microscope image of a polyimide fill tube attached to a plastic shell show in Fig. 9 (top) and an Xray radiograph image of the same attachment shown in Fig. 9 (bottom).
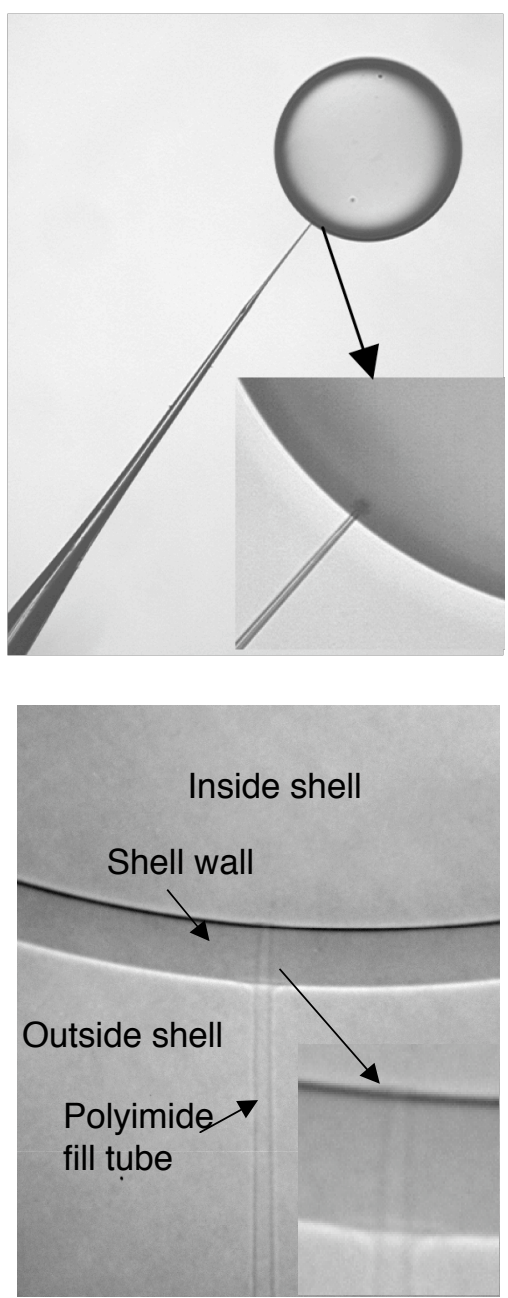

Figure 9 top: Optical microscope image. bottom: X-ray radiograph image of a polyimide fill tube attached plastic shell.

We are able to calculate the total mass of glue used from the radiographic image as shown in Fig. 10. The masses of the glue, both in the hole and at the surface of the shell around the tube, are calculated to be 0.6 and 1.5 $\mathrm{ng}$, respectively, thus resulting in a total of $2.1 \mathrm{ng}$ of glue, less than NIF specification of $2.5 \mathrm{ng} .{ }^{8}$ 

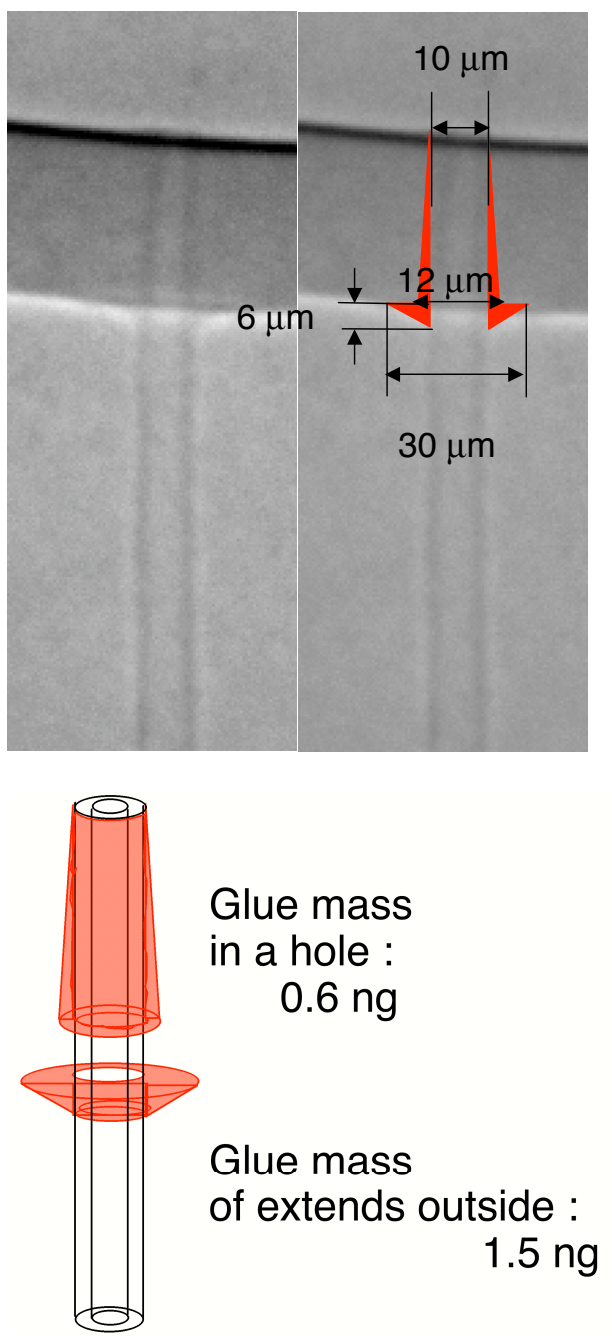

Figure 10. We can calculate the total glue mass using the $\mathrm{X}$-ray radiograph image.

\section{SUMMARY}

We have made polyimide fill tubes with NIF relevant dimensions. We have demonstrated that one can use an Excimer laser to drill a $5 \mu \mathrm{m}$ diameter through hole in the wall of a NIF dimension GDP shell, and can then create a 10-15 $\mu \mathrm{m}$ diameter, 20-40 $\mu \mathrm{m}$ deep counterbore centered on the through hole with the same laser. Lastly, we have demonstrated that we can glue our polyimide fill tubes into shells using a minimum amount of UV cure epoxy.

\section{ACKNOWLEDGEMENT}

This work was performed under the auspices of the U.S. Department of Energy by the University of California Lawrence Livermore National Laboratory under contract No. W-7405-Eng-48 and by General Atomics under Contract DE-AC03-95SF20732.

\section{REFERENCES}

1. S. W. HAAN, et al., "Update on Specifications for the NIF Ignition Targets, and Their Rollup into an Error Budget," Fusion Sci. Technol. 49, 553 (2006). See also S. W. HAAN, et al., "Update on Specifications for the NIF Ignition Targets," Fusion Sci. Technol., this issue.

2. E. I. MOSES and C. R. WUEST, "The National Ignition Facility: Laser Performance and First Experiments," Fusion Sci. Technol. 47, 314 (2005); G. H. MILLER, E. I. MOSES, and C. R. WUEST, "The National Ignition Facility," Opt. Eng. 43, 2841 (2004).

3. J. EDWARDS, et al., "The Effects of Fill Tubes on the Hydrodynamics of Ignition Targets and Prospects for Ignition," Phys. Plasmas 12, 056318 (2005).

4. N. IZUMI , et al., "Experimental Study of Fill-tube Hydrodynamic Effects on Implosions Using Capsules with Plastic Stalks", presented at the $48^{\text {th }}$ Annual Meeting of the Division of Plasma Physics, Philadelphia, Pennsylvania, October 30-November 3, 2006; S. H. LANGER, N. IZUMI, T. R. DITTRICH, and S. W. HAAN, "Simulations of X-ray Emission from Omega Fill Tube Experiments", presented at the $12^{\text {th }}$ International Workshop on Radiative Properties of Hot Dense Matter, Albufeira, Algarve, Portugal, September 11-15, 2006, proceedings to be published.

5. K. C. CHEN, et al., "Fabrication of Graded Germanium-Doped CH Shells, " Fusion Sci. Technol. 49, 750 (2006).

6. AURUM ${ }^{\circledR}$ made in Mitsui Chemicals, Shiodome City Center, 5-2, Higashi-Shimbashi 1-Chome, Minato-ku, Tokyo 105-7117, Japan.

7. Thermorex ${ }^{\circledR}$ made by Gunze, 1 Zeze, Aono-cho, Ayabe City, Kyoto 623-8511, Japan.

8. S. HAAN, private communication. 